\title{
PLANEJAMENTO ESTRATÉGICO DE COMUNICAÇÃO ORGANIZACIONAL PARA UMA EMPRESA DE INTERNET: O CASO DA PLATAFORMA AGENDA FÁCIL
}

\author{
Juliane Bazzo ${ }^{1}$ \\ Mariana Skroch Domakoski ${ }^{2}$ \\ Ronald Adriano Peña Arauz ${ }^{3}$
}

\section{RESUMO}

Este artigo apresenta o processo de elaboração do planejamento estratégico de comunicação organizacional desenvolvido no âmbito de uma consultoria para empresa de internet Agenda Fácil, que oferece uma plataforma de agendamento online de serviços. A partir desse caso prático, o trabalho busca discutir a metodologia de construção de planejamentos de comunicação organizacional e, de modo particular, a especificidade de realizá-los para empresas que nascem, crescem e operam exclusivamente pela internet. Parte-se do pressuposto de que o cenário de revolução tecnológica da atualidade desafia, com sua velocidade informacional, o ato de planejar, que se calca num esforço reflexivo calculado e não precipitado. A despeito disso, constata-se que o planejamento, enquanto ferramenta de ação, demonstra grande capacidade de adaptação contextual e perdura como instrumento ímpar para a realização de uma comunicação organizacional eficaz.

Palavras-chave: Comunicação organizacional; Planejamento estratégico; Revolução tecnológica; Empresas de internet.

\begin{abstract}
This article presents the process of formulating the strategic planning for organizational communication, developed in the context of a consulting process, for the internet company Agenda Fácil, which provides a platform for online scheduling services. As of this case study, the present work discusses the methodology of building plans of organizational communication, in particular the specificity of accomplishing them to companies that are born, grow and operate exclusively on the internet. It starts from the assumption that the scenario of the current technological revolution, with its informational speed, challenges the act of planning, a reflective, calculated and not precipitate effort. Nevertheless, it is quite clear that the planning, as a tool for action, not only has a great aptitude for contextual adaptation but also endures as a unique tool for conducting an effective organizational communication.
\end{abstract}

\footnotetext{
${ }^{1}$ Jornalista, mestre em Antropologia Social pela Universidade Federal do Paraná (UFPR). Consultora da empresa Agenda Fácil.

${ }^{2}$ Jornalista pela Universidade Federal do Paraná (UFPR). Consultora da empresa Agenda Fácil.

${ }^{3}$ Graduado em Comunicação Social/Publicidade e Propaganda pela Universidade Federal do Paraná (UFPR). Cofundador e Diretor de Marketing da empresa Agenda Fácil.
} 
Keywords: Organizational communication; Strategic planning; Technological Revolution; Internet companies.

\title{
INTRODUÇÃO
}

\begin{abstract}
Ao invés de transformar-se em uma vasta biblioteca alexandrina, o mundo converteu-se num computador, num cérebro eletrônico, exatamente como numa peça infantil de ficção científica. E como nossos sentidos saíram para fora de nós, o Grande Irmão entrou, tomando-lhes o lugar. Deste modo, a menos que tenhamos consciência dessa dinâmica, entraremos numa fase de terror pânico, perfeitamente característica de um pequeno mundo ressonante de tambores tribais, de total interdependência e de forçada coexistência. (...) Em nossa longa luta para recuperar o mundo ocidental certa unidade de sensibilidade, unidade de pensamento e de sentimento, não conseguimos ficar melhor preparados para aceitar as consequências tribais dessa unidade do que estávamos preparados para a fragmentação da psique humana pela cultura tipográfica.
\end{abstract}

(Marshall McLuhan)

Quase toda alvejada pelos críticos, restou da teoria do canadense Marshall McLuhan uma ideia visionária para a época do autor que, atualmente, ecoa verossímil: a concepção de "aldeia global" (COHN, 1975). Os meios não chegaram a controlar os homens da maneira simplista imaginada por McLuhan, "esquentando" e "esfriando" grupos sociais conforme as aspirações do status quo. Mas é fato que o teórico conseguiu antever - o que fica explícito na epígrafe deste artigo - a complexidade da revolução tecnológica que o mundo, especialmente o lado ocidental, vem experimentando a partir dos anos 80 .

O trecho selecionado da obra de McLuhan aponta para as características do "paradigma da tecnologia da informação" que, segundo Castells (1996), são as seguintes: a informação figura como "sua matéria-prima", ou seja, envolve tanto informação que impacta sobre a tecnologia, quanto tecnologia para impactar sobre a informação; registra alto grau de "penetrabilidade", haja vista que a informação torna-se parte integral de todas as atividades humanas; opera com uma "lógica de redes", que lhe confere capacidade de ação e de reação diante da imprevisibilidade inerente ao seu próprio contexto de evolução; por fim, tem como marca a convergência tecnológica em "sistemas altamente integrados", que experimentam constante mutação.

Se as mudanças se demonstraram grandiosas, semelhante magnitude adquiriram os desafios para os profissionais do campo de comunicação nesse cenário. 
Nisso, McLuhan foi igualmente profético, na epígrafe destacada, acerca da dificuldade de abarcar as consequências desse novo paradigma. A trajetória do planejamento estratégico de comunicação organizacional, enquanto ferramenta da área, mostra-se reveladora de tal panorama, ao mesmo tempo, intrincado e instigante.

O planejamento estratégico é um instrumento empresarial nascido nos anos 50 nos Estados Unidos, como resposta das organizações desse país a uma sociedade que intensificava seu ritmo de crescimento econômico. A essa época, as empresas norteamericanas, que começavam a se tornar multinacionais, perceberam uma grande perspectiva de transformação em seus modos de atuar. Em virtude disso, lançaram mão do planejamento para se antecipar e vivenciar as mudanças de maneira bem-sucedida (KUNSCH, 2002 [1986]).

De lá para cá, o planejamento vem se demonstrando um instrumento ímpar para compreensão e intervenção em um mundo cada vez mais complexo, que reúne simultaneamente tanto processos de globalização, quanto de defesa de tradições locais, ambos fomentados pelos aparatos tecnológicos. Nesse cenário em que se ampliam sobremaneira as possibilidades comunicacionais de diferentes setores, as organizações são convocadas a serem abertas e transparentes, a criar canais de interação com a sociedade e a ela prestar contas. Para tanto, não podem mais perder de vista todos os seus públicos de relacionamento, pois um filão antes distante pode emergir repentinamente e se tornar central (KUNSCH, 1999; REGO, 2002).

Nesse quadro, a área de comunicação corporativa, antes periférica, vai conquistando importância estratégica e também ela lança mão do planejamento, enquanto ferramenta propícia ao relacionamento customizado com os diversos públicos em contato com as organizações (id.). Contudo, justamente nesse momento em que o planejamento de comunicação encontra respaldo para demonstrar seu valor às empresas, menor espaço temporal estas têm para planificar suas ações.

Verifica-se, assim, um paradoxo: a multiplicidade e simultaneidade das mudanças da atualidade - que não impactam apenas o domínio da tecnologia, mas também o das relações humanas, entre outros - tornam imprescindível que as organizações se planejem estrategicamente; porém, essa conjuntura desafia o próprio planejamento que, segundo explica Oliveira (2002), constitui um processo reflexivo 
complexo sobre "estados de futuro desejados", que visa à mudança organizacional, mas assertiva e não precipitada.

Tal situação adquire ainda maior ênfase em empresas que operam exclusivamente na e via internet, lugar onde a aceleração da revolução tecnológica se expressa a toda potência. Esse é o caso da plataforma Agenda Fácil, organização sob análise no presente artigo.

\section{COMUNICAÇÃO PARA UMA EMPRESA DE INTERNET}

Quem nunca teve um problema com agendamento de serviços? Inspirados por esse questionamento e com o objetivo de fornecer soluções inovadoras para facilitar o dia a dia das pessoas, quatros sócios fundaram, em junho de 2011, a plataforma www.agendafacil.com, cuja funcionalidade é possibilitar agendamentos online de diversos tipos de serviços, desde consultas médicas até aluguel de quadras esportivas. Tal variedade situa-se como principal diferencial da organização Agenda Fácil em relação à concorrência que, na sua maioria, foca em apenas uma área de mercado.

Nos sistemas desenvolvidos pela Agenda Fácil, o internauta tem a seu alcance uma ampla gama de informações sobre profissionais e empresas da área desejada. De forma fácil, rápida, gratuita e segura, ele pode agendar um horário, considerando a qualificação e a disponibilidade dos contatos apresentados. Os profissionais e empresas cadastrados, por sua vez, têm a garantia de que as particularidades do agendamento de seus serviços serão atendidas, tendo total controle sobre os seus horários. A plataforma disponibiliza diversas ferramentas que auxiliam no monitoramento de agenda e proporcionam otimização do tempo.

A ideia do negócio surgiu quando dois dos sócios, que possuem experiências em administração e negócios, perceberam a carência existente no Brasil de uma página que permitisse o agendamento de serviços diversos pela internet. Em países como os Estados Unidos, a prática é comum, com sites de grande sucesso, como o ZocDoc ${ }^{4}$. Após tal constatação, fizeram o convite de sociedade a outros dois profissionais, com vivência nas áreas de tecnologia e comunicação, a fim de desenvolver a plataforma.

\footnotetext{
${ }^{4}$ www.zocdoc.com. O ZocDoc é um portal de agendamentos de consultas médicas, restrito aos Estados Unidos, que começou em 2007, com a oferta de dentistas em Nova Iorque. Passado algum tempo, passou a disponibilizar agendamento com vários outros profissionais da área e atingiu quase 20 cidades do país.
} 
A Agenda Fácil nasceu com o formato de uma startup, um conceito empresarial norte-americano que chegou ao Brasil no período conhecido como "bolha da internet”, entre 1996 e 2001. Refere-se a “(...) um grupo de pessoas à procura de um modelo de negócios repetível [produção em escala potencialmente ilimitada] e escalável [crescimento sem grandes alterações no modelo de negócio], trabalhando em condições de extrema incerteza" (GITAHY, 2010).

Em agosto e setembro de 2011, a Agenda Fácil participou da primeira edição do Startup Farm, programa brasileiro privado de capacitação de empreendedores digitais ${ }^{5}$. Dado o destaque alcançado nessa iniciativa, a empresa recebeu o convite para atuar como parceira a partir da segunda edição, que seria realizada em outubro e novembro de 2011. Desde então, a Agenda Fácil é responsável pelo sistema que permite o agendamento de encontros entre os empreendedores participantes e os profissionais mentores do Startup Farm.

Atualmente, outros dois sistemas de agendamentos compõem a plataforma: o Agenda Beleza, que conecta clientes a salões de beleza, clínicas de estética, personal stylists, entre outros serviços do gênero, e o Agenda Saúde, que objetiva intermediar o contato de pacientes para com médicos, terapeutas, enfermeiros, dentre outros profissionais.

A comunicação, desde o início, foi sentida como uma necessidade de negócio para os sócios da Agenda Fácil. De saída, eles identificaram três frentes de trabalho nesse sentido: desenvolvimento de um site institucional, atuação em redes sociais e ações de assessoria de imprensa. Com isso em mente, partiram em busca de um profissional que os pudesse auxiliar nessa empreitada. Como desdobramento, houve a contratação, no início do ano de 2012, de uma consultoria na área, que recebeu uma questão-chave: por onde começar o trabalho de comunicação organizacional?

A consultoria apontou como primeiro passo o desenvolvimento de um planejamento estratégico, que permitiria conhecer adequadamente o campo de atuação da empresa para, então, arquitetar intervenções comunicacionais coerentes e consistentes. A alternativa foi prontamente aceita pelos sócios da Agenda Fácil que, assim, criaram o ambiente ideal para iniciar qualquer trabalho em comunicação. Logo, a Agenda Fácil não

\footnotetext{
${ }^{5}$ http://startupfarm.com.br. O programa envolve atividades práticas de formação, promoção de palestras, apresentação de depoimentos de empreendedores, encontros para troca de ideias e exposição dos projetos dos participantes a investidores de mercado.
} 
incorreu em uma fragilidade muito comum no universo corporativo, no qual determinadas empresas, quando se trata de comunicação organizacional, costumam focar na produtividade em detrimento do planejamento. Decisão esta pautada, muitas vezes, pela aceleração dos acontecimentos no cenário empresarial contemporâneo, porém, justamente por isso, deveras arriscada.

\section{METODOLOGIA DE PLANEJAMENTO}

O planejamento estratégico de comunicação organizacional desenvolvido para a Agenda Fácil foi construído sob inspiração da metodologia traçada por Margarida Maria Krohling Kunsch. Em suas pesquisas e publicações, Kunsch tem, de forma pioneira, revisado sistematicamente a literatura disponível acerca do planejamento estratégico e adaptado ao contexto comunicacional.

A autora delimita diversas fases metodológicas para o desenho de planejamentos estratégicos em comunicação, as quais, acreditamos, podem ser agrupadas em três macroetapas principais: desenvolvimento de diagnóstico, delimitação de estratégias de ação e, por fim, definição de mecanismos de monitoramento e avaliação de resultados. O sucesso do planejamento depende da sinergia entre esses três momentos: sendo apenas um deles ineficiente, todo o restante será impactado.

Antes de tudo, porém, a teórica destaca a necessidade de obtenção do comprometimento da administração superior da empresa para qual se propõe o planejamento, no sentido de sensibilizá-la para a importância estratégica da comunicação no universo corporativo contemporâneo. Isso, conforme descrito antes, foi conquistado no caso da Agenda Fácil, haja vista que os sócios do empreendimento já visualizavam a comunicação como um elemento imprescindível ao negócio.

A descrição sucinta das três macroetapas supracitadas, que vem a seguir, baseia-se especialmente em Kunsch (2002[1986]), obra central no que tange à questão do planejamento estratégico no trabalho da autora.

\subsection{DESENVOLVIMENTO DE DIAGNÓSTICO}

A realização do diagnóstico consiste em conhecer a fundo a organização para a qual se realizará o planejamento estratégico. Nesse processo, um estágio crucial está na 
identificação dos públicos - ou seja, todos os grupos sociais, internos e externos à empresa, a ela relacionados -, pois as ações de comunicação planejadas serão pensadas e executadas para eles e/ou com eles. Os públicos devem ser delimitados de acordo com seu grau de relacionamento com a organização e precisam ser ouvidos no processo de diagnóstico, para que sua história, seu perfil e suas necessidades sejam conhecidas.

Além disso, na etapa de diagnóstico, procede-se o mapeamento da estrutura física, humana e hierárquica da empresa; de suas filosofias e políticas de ação; de seu sistema de comunicação interno e externo; de eventuais conflitos e problemas de imagem perante a opinião pública de um modo geral, bem como em relação a cada um dos públicos de relacionamento de forma particular6 ${ }^{6}$ Trata-se, por conseguinte, de uma pesquisa institucional que objetiva descrever o histórico e atuação presente da empresa; apontar e refletir sobre problemáticas existentes; assim como vislumbrar diretrizes para ações eficazes de futuro.

Tal levantamento pode lançar mão de entrevistas com lideranças organizacionais e representantes-chave dos públicos de relacionamento, assim como de análises do planejamento estratégico global da empresa (se houver), de seu material informativo e promocional, de publicações institucionais, da clipagem de mídia, entre outras ferramentas julgadas úteis ao levantamento de informações.

Uma vez reunidos os dados, deve ocorrer a sistematização do diagnóstico em documento: esse processo intelectivo propicia a quem planeja a reflexão analítica e crítica sobre tudo aquilo que foi pesquisado, permitindo assim identificar os pontos "nevrálgicos", as prioridades e os caminhos para a ação. O diagnóstico formalizado dá origem a um briefing, que consiste numa síntese de tal levantamento, capaz de operar como referencial para as etapas subsequentes de desenho do planejamento estratégico.

\subsection{DELIMITAÇÃO DE ESTRATÉGIAS DE AÇÃO}

Com o diagnóstico finalizado, é possível estabelecer políticas, objetivos e metas que orientarão o desenvolvimento das estratégias de ação do planejamento.

\footnotetext{
${ }^{6}$ Entende-se aqui opinião pública como aquela que se materializa sob influência do sistema social vigente, bem como dos meios de comunicação de massa, e expressa, de maneira dinâmica e difusa, reações a fenômenos sociais, de fundo político ou não. Já o público, por sua vez, configura um grupo organizado em torno de questões comuns que, a partir do debate e da reflexão, reverbera posturas unificadas de ação (cf. FREITAS, 2012).
} 
Estabelecer políticas de comunicação significa elaborar um conjunto de princípios e normas capazes de nortear todas as intervenções organizacionais nessa área, sendo substrato para tomadas de decisão assertivas. Trata-se de uma espécie de código de ética, que contém a missão, os valores, a visão de comunicação da empresa, seus procedimentos comunicacionais-chave, bem como os papéis estratégicos que a comunicação deve desempenhar naquele universo corporativo. Importa destacar que as políticas de comunicação precisam, necessariamente, estar em consonância com as políticas globais de atuação da empresa.

Afinados com as políticas de comunicação, são elaborados os objetivos do planejamento, que apontam para os resultados desejados com a realização das ações estratégicas. Os objetivos, de curto, médio e/ou longo prazo, devem ser críveis - não baseados em suposições, mas alicerçados nas demandas evidenciadas pelo diagnóstico e quantificáveis - com possibilidade de se traduzirem em metas, que configuram o prazo temporal no qual se espera que os resultados sejam alcançados.

Feito isso, é chegada a hora de traçar as ações que, de fato, materializam o planejamento estratégico, permitindo que este contemple dimensões táticas e operacionais ${ }^{7}$. Nessa etapa, o planejamento comporta a elaboração de projetos, planos e programas $^{8}$. Tais documentos possibilitam detalhar atividades e ferramentas, com seus objetivos e metas próprios, para intervenções específicas em comunicação, focadas em áreas de negócio e/ou em públicos organizacionais.

Nesse momento, o planejador exercita sua criatividade, elenca alternativas e elege prioridades. É muito importante que ele desenvolva justificativas para as ações de cada projeto, plano ou programa: isso permite testar se as escolhas são factíveis, como

\footnotetext{
${ }^{7}$ Enquanto o planejamento estratégico pensa a empresa como um todo, o planejamento tático se volta à otimização de determinadas áreas organizacionais e o planejamento operacional trata do processo de implantação propriamente dito das decisões táticas. Os três tipos de planejamento são complementares. Pode-se discuti-los separadamente, enquanto exercício acadêmico, a fim de pensar sobre os níveis de complexidade da ação de planejar. Porém, não é possível separá-los de fato (ALBUQUERQUE, 1983; KUNSCH, 2002 [1986], 1997; OLIVEIRA, 2002).

${ }^{8}$ Segundo Kunsch (2002[1986]), os projetos seriam mais complexos que os planos e estes mais complexos que os programas. Os programas podem fazer parte tanto de projetos quanto de planos, haja vista que se detêm propriamente na execução de ações, enquanto os dois primeiros abarcam conteúdo de ordem mais tática. Por exemplo, em um planejamento de comunicação organizacional, no qual o diagnóstico revelasse problemas de imagem da empresa perante a opinião pública, um projeto poderia contemplar estratégias de ação para o resgate e fortalecimento da imagem; dentro dele, um plano seria capaz de propor a remodelação da identidade visual corporativa; e por fim, um programa vinculado a eles trataria da promoção de patrocínios capazes de evidenciar a marca.
} 
também facilita sua apresentação e aprovação diante do corpo diretivo da organização, o qual deve dar o aval à execução do planejamento.

Para fechar a fase de delimitação das estratégias de ação, faz-se necessário levantar todos os recursos humanos, materiais e financeiros imprescindíveis à execução dos projetos, planos e programas arquitetados. Tal mapeamento permitirá a elaboração de um orçamento global do planejamento estratégico, capaz de operacionalizá-lo de maneira racional.

\subsection{DEFINIÇÃO DE MECANISMOS DE MONITORAMENTO E AVALIAÇÃO}

Uma vez aprovadas pela organização demandante, as ações do planejamento estão aptas à implantação. Entre o planificado e a prática, quase sempre ocorrem eventos imprevistos, que podem exigir mudanças de percurso. A fim de dar conta de tais aspectos contingenciais, o planejamento deve abarcar mecanismos de monitoramento na implementação das ações. Ferramentas como agendas, arquivos, cronogramas, fluxogramas, clipping de mídia, entre outras, embora aparentemente simples, permitem o acompanhamento das atividades realizadas e a identificação de necessidades de alteração em seu escopo, de modo que isso possa ser providenciado a contento.

Ademais, os mecanismos de controle oferecem sustento à avaliação dos resultados enredados pelo planejamento. Trata-se de um momento sensível do processo, pois expressiva parte dos êxitos em comunicação organizacional possui caráter intangível e se revela em médio e longo prazo. Os mecanismos de controle, portanto, figuram como bons pontos de partida para a construção de indicadores avaliativos, que precisam ser capazes de medir o sucesso (ou insucesso) das ações perante os diversos públicos corporativos.

Os indicadores falam de comportamentos e atitudes dos públicos. Entre os mais utilizados estão as referências à organização na imprensa convencional e na internet; as cartas e e-mails com comentários e críticas; o fluxo de reclamações; a produtividade funcional; a incidência de conflitos entre colaboradores; o volume de negócios gerado pela empresa. Os indicadores podem também ser delineados por meio de pesquisas de opinião com os públicos. 
É importante elaborar relatórios de acompanhamento periódicos, com o intuito de avaliar a evolução dos indicadores planificados. Vale destacar que não existe fórmula de avaliação pronta, mas se mostra fundamental que o planejamento contemple tal tópico, traçando indicadores prévios, bem como estabelecendo meios para seu desenvolvimento e acompanhamento.

\section{O PLANEJAMENTO NA PRÁTICA}

Ciente de que uma metodologia não pode figurar como camisa de força, mas sim enquanto substrato para qualquer intervenção, a equipe responsável pelo planejamento de comunicação da Agenda Fácil trabalhou na construção de um documento orientado pelo arcabouço teórico especificado no item anterior e, ao mesmo tempo, customizado ao perfil, à realidade e às necessidades da empresa em questão.

\subsection{CONSTRUÇÃO DO DIAGNÓSTICO}

O diagnóstico foi gerado a partir de três estratégias concomitantes: promoção de oficinas e entrevistas com os sócios organizacionais para levantamento de dados; mapeamento detalhado de públicos de relacionamento; e análise minuciosa da concorrência. Houve a realização de duas oficinas, nas quais os sócios puderam ofertar informações de forma sistematizada à equipe responsável pelo planejamento estratégico, como também tiveram a oportunidade de construir coletivamente conteúdos orientadores ao trabalho em comunicação organizacional.

A primeira oficina procurou conduzir os participantes a uma reflexão sobre a empresa como um todo, convidando-os a traçar a missão, a visão e os valores da Agenda Fácil; a identificar seus públicos de relacionamento próximo, intermediário e distante; a refletir sobre os pontos fortes e fracos de seus concorrentes; e, por fim, a inventariar possíveis situações de crise, que exigiriam intervenções específicas em comunicação.

A segunda oficina debruçou-se especificamente sobre os aspectos comunicacionais na organização. Nessa ocasião, os participantes estabeleceram juntos a missão e os valores de comunicação da Agenda Fácil, bem como refinaram seus campos de interesse de investimento nessa área, a partir da disposição de possíveis ferramentas comunicacionais a serem empregadas. 
Em ambas as oficinas, a metodologia de aplicação foi a mesma. Utilizou-se a técnica de brainstorming, na qual os participantes, em rodadas sucessivas, foram lançando ideias em palavras-chave sobre um assunto determinando. Ao longo do processo, houve o registro de todas as ideias em um quadro, em forma de lista ou por meio de desenhos, para que todos pudessem visualizar o andamento das discussões. Concluído esse processo, a equipe responsável pela construção do planejamento estratégico lapidou os conteúdos reunidos nas oficinas, para posterior referendo dos sócios da Agenda Fácil.

A equipe também realizou uma entrevista pessoal aprofundada com o profissional que gerencia a área de marketing da Agenda Fácil. Baseada em questionário sugerido por Kunsch (2002 [1986]), a entrevista buscou entender o organograma organizacional, o relacionamento com os públicos corporativos, o nicho de negócio da empresa, seus diferenciais em relação à concorrência e, por fim e especialmente, como a comunicação é pensada em tal contexto.

Os dados gerados pelas oficinas e pela entrevista permitiram avançar nas duas outras frentes estabelecidas para o diagnóstico. Desse modo, ocorreu o traçado de um perfil minucioso de 15 públicos organizacionais, segmentados em de relacionamento próximo, intermediário e distante. A descrição sobre cada grupo contemplou informações acerca da comunicação entre dado público e a empresa (caso já existente), como também as expectativas dos sócios quanto ao relacionamento com determinado stakeholder. A partir disso, foi possível refletir sobre como a comunicação poderia construir ou aprimorar os vínculos da Agenda Fácil com seus vários públicos, já vislumbrando eventuais estratégias de ação para tanto.

Houve ainda a identificação de oito empresas de internet que disponibilizam sites de agendamento com semelhanças em relação à Agenda Fácil. Essas empresas foram cuidadosamente analisadas e classificadas como concorrentes diretos e indiretos. Tal mapeamento averiguou as ações em comunicação encabeçadas por todas, entre elas, a presença em redes sociais e sua inserção na imprensa. Ademais, tal investigação objetivou sensibilizar os sócios da Agenda Fácil a transcender a visão de concorrente enquanto inimigo mercadológico tão somente. Das empresas analisadas, algumas não se colocam como concorrentes diretas - por atuarem num raio geográfico completamente diferente —, mas possuem boas práticas em comunicação, nas quais a Agenda Fácil pode se espelhar. 
O diagnóstico foi então concluído: sistematizou os pontos fortes e frágeis da organização, tendo como pano de fundo permanente a comunicação organizacional, assim como apontou caminhos para as estratégias de ação. A seguir, será apresentado um apanhado dos principais pontos desse documento ${ }^{9}$.

Um dos importantes diferenciais identificados foi o fato de a empresa ter captado a tendência do agendamento online de serviços quando esta ainda dá os primeiros passos no Brasil. Assim, a organização possui uma vantagem competitiva em relação à concorrência. Entretanto, verificou-se uma considerável lacuna no que diz respeito ao relacionamento da Agenda Fácil com sua rede de stakeholders, especialmente com os clientes interessados em disponibilizar seus serviços nos sites de agendamento e com os futuros usuários da plataforma, os dois públicos diretamente responsáveis pelo fomento dos negócios corporativos.

O diagnóstico propiciou a tomada de consciência por parte da empresa de que este vínculo não está dado apenas com a identificação de uma tendência de mercado, mas precisa ser construído por meio de canais de comunicação estruturados. Tal constatação ganha ainda maior relevância quando se leva em conta que clientes e usuários da Agenda Fácil não constituem públicos homogêneos: eles podem envolver uma grande variedade de grupos, haja vista a proposta da organização em trabalhar com agendamento de serviços dos mais variados tipos. Essa característica, conforme já mencionado antes, também opera como diferencial da empresa, já que seus concorrentes concentram-se em nichos específicos.

Por ora, existem somente três áreas de agendamento previstas na plataforma - uma voltada às startups, outra à beleza e uma última à saúde -, mas essa gama deve aumentar, o que exigirá conhecer mais de perto a realidade, as aspirações e as expectativas desses subpúblicos de clientes e usuários, bem como desenhar instrumentos de comunicação dirigida para cada uma deles. Logo, o cascateamento de stakeholders da Agenda Fácil mostrou grande complexidade, consoante à diversidade que o mundo virtual se mostra capaz de reunir.

\footnotetext{
${ }^{9}$ Nesta apresentação do diagnóstico do planejamento de comunicação da Agenda Fácil, a questão da confidencialidade foi respeitada no que tange à não exposição de certos pontos considerados estratégicos à organização. O mesmo se deu na descrição das estratégias de ação do planejamento, em item subsequente. Acredita-se que isso não compromete os objetivos do presente artigo, uma vez que os aspectos confidenciais são ínfimos se comparados ao conteúdo global do planejamento aqui exposto.
} 
Comunicar nesse contexto é, portanto, um desafio, pois exige da organização relacionar-se com segmentos muito diversificados, de maneira assertiva, sem se perder num caos informacional. Para tanto, o diagnóstico apontou a relevância de um trabalho integrado entre os setores comercial, de marketing e de comunicação, uma potente aliança ainda subutilizada no cenário organizacional em questão.

Outra constatação importante foi a fase inicial em que a grande maioria dos concorrentes se encontram em termos de comunicação. Nesse ponto, a Agenda Fácil pode considerar-se uma empresa à frente, por estar preocupada e investindo na área. Sendo assim, o diagnóstico apontou para a oportunidade de implantação de uma estrutura integrada de comunicação na Agenda Fácil, que articule site institucional, mídias sociais e assessoria de imprensa, a princípio. Isso seria um diferencial expressivo em relação à comunicação da concorrência que, de modo geral, foca em apenas uma ou duas dessas frentes.

O diagnóstico também assinalou a necessidade de elaboração de um plano de gerenciamento de crises. Nos debates realizados nas oficinas, verificou-se que as situações capazes de abalar a imagem da Agenda Fácil perante seus stakeholders são relativamente numerosas. Esse panorama não constitui novidade para empresas que nascem, crescem e atuam exclusivamente no instável espaço virtual, mas é, sim, algo intrínseco à sua operação. Tal quadro, todavia, revela-se mais sensível no caso da Agenda Fácil, porque sua relação com stakeholders prioritários - clientes e usuários - ainda carece de aprofundamento.

Erros na execução dos sistemas de agendamento, vazamento de dados privativos e falta de procura por determinados serviços disponibilizados na plataforma são algumas das situações elencadas como possíveis desencadeadoras de crises e exigem, desse modo, atenção planejada. Mostrou-se preciso planificar ações preventivas de comunicação, capazes de dar conta das repercussões que os sistemas possam gerar, assim como de transformar quaisquer negatividades em subsídios para melhorias ágeis e eficientes.

Por fim, o diagnóstico convidou os sócios da Agenda Fácil a cuidarem de sua ambiência organizacional, por intermédio de investimento em comunicação interna. Apesar de nenhum ponto frágil ter sido identificado nesse âmbito, o fato de a equipe da empresa estar em pleno crescimento torna oportuno o desenho de ações estruturadas, para 
garantir a fluência comunicacional entre os colaboradores e a manutenção de um clima corporativo equilibrado.

\subsection{ESTRATÉGIAS DE AÇÃO}

A metodologia participativa empregada no diagnóstico permitiu que os sócios da Agenda Fácil traçassem a missão da comunicação na empresa, sob assessoria da equipe responsável pela construção do planejamento estratégico. Estabeleceu-se que, na organização, a comunicação ambiciona: "Trabalhar para que os stakeholders vejam a Agenda Fácil como uma referência nos diversos campos de atuação organizacional, a partir da oferta de informações inovadoras e atualizadas, bem como por meio de uma postura transparente em todas as interações com os públicos, independentemente do veículo utilizado". O grupo também definiu os valores que devem permear a comunicação praticada pela Agenda Fácil. São eles: ética, agilidade, retidão, conhecimento e compreensão dos assuntos tratados, atualidade, empatia, organização e pontualidade.

Com base nisso, houve o estabelecimento dos objetivos gerais e específicos das ações estratégicas em comunicação abarcadas pelo planejamento. Construir rotinas de comunicação no site institucional, nas redes sociais e em assessoria de imprensa figurou como aspiração maior. Entre as específicas, ingressaram: cuidar do posicionamento e relacionamento da Agenda Fácil perante todos os seus públicos; atrair visitantes ao site institucional; aumentar o volume de acessos ao blog corporativo; aumentar o número de seguidores nas redes sociais da empresa e de seus sistemas; divulgar a organização e seus produtos por meio da imprensa; gerar contatos espontâneos de jornalistas interessados em realizar reportagens que tratem, direta ou indiretamente, sobre a Agenda Fácil e seus negócios; e gerenciar crises caso se configurem.

Os objetivos subsidiaram a elaboração de uma lista ampla de estratégias de ação - 35 no total. Cada uma delas foi devidamente descrita e justificada, ou seja, houve o cuidado de destacar por que seriam interessantes e eficazes à Agenda Fácil. Além disso, a exposição de cada estratégia incluiu: delimitação de públicos-alvo; metodologia de execução; ferramentas de operação e de controle de resultados; profissionais necessários à implementação; metas e prazos de realização; custos envolvidos; e mecanismos de avaliação. 
Houve preocupação em segmentar as estratégias para que estas alcancem maior eficácia. De um lado, ocorreu a delimitação de estratégias institucionais, ou seja, focadas em fortalecer o posicionamento da Agenda Fácil enquanto empresa perante toda sua rede de stakeholders. Tais intervenções se propõem a trabalhar a imagem organizacional, fomentar negócios de modo geral e alavancar parcerias das mais diversas. Por outro lado, foram desenhadas estratégias específicas destinadas à comunicação com públicos das áreas de agendamento da plataforma, no momento, startups, beleza e saúde.

Por fim, listaram-se estratégias emergenciais, que foram colocadas em prática com prioridade, como o abastecimento do site institucional e do blog corporativo, além das ações preparatórias ao lançamento do sistema Agenda Beleza, o qual se encontrava em contagem regressiva no período em que o planejamento estava sendo desenvolvido. Também nesse âmbito aconteceu a contratação de uma agência de comunicação, para ficar responsável pela operacionalização do planejamento como um todo.

\section{CONSIDERAÇÕES FINAIS}

Nesses tempos em que a tecnologia é capaz de conferir à informação uma velocidade sem precedentes, o ponto alto de um planejamento estratégico em comunicação - especialmente para uma empresa cuja vida ocorre na internet, situação da Agenda Fácil - é o processo de fazer pensar. Ao planejar em conjunto com os profissionais de comunicação, os sócios da organização encontraram um momento único para refletir sobre a identidade corporativa, bem como acerca de sua projeção correta e eficaz em imagem diante de públicos de interesse. Se, de saída, eles já visualizavam a comunicação como elemento importante aos negócios, mas não tinham muito claros os porquês, o percurso de construção do planejamento retirou qualquer opacidade, deixando claras necessidades, demandas e prioridades.

Assim, se num primeiro momento o planejamento exige que seus participantes se desliguem um tanto da prática cotidiana do trabalho - algo cada vez mais difícil diante das exigências mercadológicas por rapidez e produtividade -, a sistematização dele permite logo vincular o pensar e o fazer, com o diferencial de possibilitar que tal conexão ocorra mais assertivamente, sem precipitações e, portanto,

com maiores chances de resultados eficientes aos negócios. Nesse sentido, o planejamento estratégico, enquanto elemento imprescindível para a área de comunicação, 
demonstra-se atemporal: ele foi ferramenta importante quando um mundo globalizado começava a se desenhar e permanece sendo neste momento de grande revolução tecnológica.

\section{REFERÊNCIAS}

ALBUQUERQUE, Adão Eunes. Planejamento das relações públicas. 2 ed. Porto Alegre: Sulina, 1983.

BAZZO, Juliane; DOMAKOSKI, Mariana Skroch. Planejamento Estratégico de Comunicação do AgendaFácil.com. Documento interno inédito. Curitiba, abril, 2012.

CASTELLS, Manuel. A sociedade em rede. Vol 1. São Paulo: Paz e Terra, 1996.

COHN, Gabriel. O meio é a mensagem: análise de McLuhan. In: (org.). Comunicação e indústria cultural. São Paulo: Nacional, 1975. p. 363-371.

FREITAS, Sidinéia Gomes. Formação e desenvolvimento da opinião pública. Disponível em: <www.portal-rp.com.br/bibliotecavirtual/opiniaopublica/0017.htm>. Acesso em: Abril 2012.

KUNSCH, Margarida Maria Krohling. Novos desafios para o profissional de comunicação. In: LABJOR. Estado, mercado e interesse público. Brasília: Banco do Brasil, 1999. p. 49-54.

Planejamento de relações públicas na comunicação integrada. São Paulo: Summus, 2002 [1986].

MCLUHAN, Marshall. A galáxia de Gutenberg. 2 ed. São Paulo: Nacional, 1977 [1962].

GITAHY, Yuri. Afinal, o que é uma startup? Disponível em: < http://exame.abril.com.br/pme/dicas-de-especialista/noticias/o-que-e-uma-startup>. Out. 2010.

OLIVEIRA, Djalma de Pinho Rebouças de. Planejamento estratégico: conceito, metodologias e práticas. 17 ed. São Paulo: Atlas, 2002.

REGO, Francisco Gaudêncio Torquato do. Comunicação empresarial/comunicação institucional. São Paulo: Torquato/Summus, 2002. 